\title{
AUGUSTO ÁNGEL MAYA: APORTES DE CALDAS AL PENSAMIENTO Y MOVIMIENTO AMBIENTAL COLOMBIANO
}

\author{
Isaías Tobasura Acuña \\ Doctor en Sociología del Medio Ambiente \\ Profesor de la Universidad de Caldas \\ isaias.tobasura@ucaldas.edu.co
}

Manizales, 2009-03-15 (Rev. 2009-04-10)

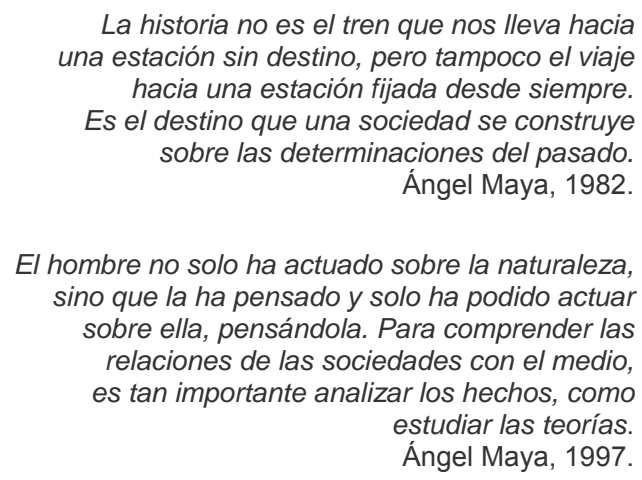

\section{RESUMEN}

Augusto Ángel Maya, nacido en Manizales en 1932, Doctor en Historia de la Universidad Gregoriana de Roma y Doctor Honoris Causa en Educación Ambiental de la Universidad Guadalajara de México, es uno de los pensadores más sobresalientes del emergente pensamiento ambiental en Colombia. Desde su trabajo como profesor, funcionario de instituciones del Estado y de organismos internacionales, ha contribuido de manera notable a la consolidación del pensamiento y movimiento ambiental colombiano en los últimos 40 años. Sus aportes se pueden sintetizar en dos: la reflexión teórica y conceptual para entender lo ambiental desde una perspectiva política, social y cultural; y la creación de herramientas de trabajo político como la educación ambiental y el impulso a la organización nacional del Movimiento Ambiental MA. Este trabajo sintetiza parte de este legado.

\section{PALABRAS CLAVE}

Ángel Maya, Historia Ambiental, Pensamiento Ambiental, Ambientalismo, Movimiento Ambiental.

\section{AUGUSTO ÁNGEL MAYA: CONTRIBUTIONS FROM CALDAS TO THE COLOMBIAN ENVIRONMENTAL THOUGHT AND MOVEMENT}

\section{ABSTRACT}

Augusto Ángel Maya was born in Manizales in 1932, with a doctorate in History from the Gregorian University of Rome and Honoris Causa Doctorate in Environmental Education from the Guadalajara University of Mexico. He's one of the most important thinkers of the emergent environmental thought in Colombia. From his work as a professor, as an official of governmental institutions and international organisms, he's contributed to the consolidation of the environmental thought and movement in Colombia for the past 40 years. His contributions can be synthesized in two: theoretical and conceptual reflection in order to understand the environmental issues from a political, social and cultural perspective; and the creation of political work tools, such as environmental education and the support of the national organization of Environmental Movement MA. This work synthesizes part of this legacy. 


\section{KEY WORDS}

Ángel Maya, Environmental history, Environmental Thought, Environmentalism, Environmental Movement.

\section{EL CONTEXTO. UNA EXPLICACIÓN NECESARIA}

Aunque las raíces del movimiento ambiental Colombiano deben rastrearse desde la Expedición Botánica, la Expedición Corográfica, las luchas comunera y de nativos y criollos por la independencia de la corona española, los decretos del Libertador sobre conservación de los recursos naturales, en los Siglos XVIII y XIX, pasando por las luchas obreras, campesinas e indígenas por la tierra y mejores condiciones laborales, de comienzos y mediados del Siglo XX, el ambientalismo en Colombia ha emergido y tomado cuerpo al calor de las luchas que los movimientos universitarios y vastos sectores de la sociedad colombiana han librado desde finales de los años 1960 y comienzos de los años 1970 para defender ecosistemas valiosos, territorios sagrados, acceder a la tierra para cultivar, y mejorar las condiciones de la salud de los obreros en las minas y fábricas.

Dentro de este gran espectro de problemas y conflictos ambientales, se destacan la defensa del parque isla de Salamanca, la Sierra de la Macarena, el parque Tayrona, la isla Gorgona, la defensa de ríos, lagunas, ciénagas, humedales, como el río Sinú, el lago de Tota, la laguna de Fúquene, la laguna del Chircal o de Sonso, la charca de Guarinocito, la lucha contra las siembras de especies exóticas como pinos y eucaliptos, la oposición de ambientalistas y ciudadanos contra la "plastificación" de la sabana de Bogotá por las empresas de flores, las luchas de los indígenas Emberá-Katíos y los U'wa en defensa de sus territorios sagrados y sus culturas ancestrales, las luchas de los obreros de las minas en diferentes regiones del país, la pelea de sectores urbanos por defender el espacio público, la resistencia de campesinos, indígenas y comunidades negras contra las fumigaciones de los cultivos ilícitos, la defensa de la seguridad alimentaria y de nuevas formas alternativas de agricultura y, más recientemente, la defensa de los derechos humanos y de la vida como valor supremo, pues no debe olvidarse que Colombia ha padecido una confrontación armada no resuelta por más de cuarenta años.

De todas formas, para que esas luchas y protestas se hubiesen constituido en un movimiento permanente de carácter nacional, y no sólo en episódicas revueltas, fueron definitivos diferentes procesos sociales, culturales, económicos y políticos que se presentaron a finales de los años 1960 y comienzos de los años 1970. Uno de ellos fue sin duda las oportunidades políticas e institucionales, surgidas como consecuencia de la Conferencia de la Naciones Unidas sobre Medio Ambiente Humano (1972), la publicación del Informe del Club de Roma Los Límites del Crecimiento (1972), la crisis petrolera (1973) -todas ellas en el ámbito internacional-, y en el ámbito nacional colombiano, la creación del Instituto de Desarrollo de los Recursos Naturales Renovables -INDERENA(1968), la promulgación del Código de los Recursos Naturales y Protección del Medio Ambiente (1974), los cuales pusieron el tema ambiental en la agenda pública.

La situación social, cultural y política que experimentaba la sociedad a finales de los años 1960 y comienzos de los años 1970, creó las condiciones para el surgimiento de movimientos sociales en diferentes partes del mundo. Uno de los más sobresalientes fue el movimiento ecologista, que más tarde dio origen a muchos de los partidos verdes de los países desarrollados y a luchas y movimientos ambientales poco institucionalizados en los países del Tercer Mundo. Colombia no fue ajena a estos procesos de acción colectiva y movilización social. El ambiente de cambio social y de fuertes movilizaciones estudiantiles y campesinas, que se presentaban en las universidades colombianas, dieron origen a los primeros intentos de creación de un movimiento ambiental con la constitución del grupo ecológico de la Universidad del Tolima a instancias del profesor Gonzalo Palomino, la inclusión de la cátedra de Ecología en el programa de Agronomía en la Universidad Nacional de Colombia en Palmira por iniciativa del profesor Hernando Patiño y la institucionalización de las jornadas ecológicas en la Universidad del Valle por iniciativa del profesor Aníbal Patiño. Aunque fueron las luchas estudiantiles y las movilizaciones 
campesinas las que sentaron las bases de lo que sería el ambientalismo colombiano, quizá lo que tuvo mayor resonancia en la opinión pública y dio origen a una mayor sensibilidad por las cuestiones ambientales fue la defensa del parque isla de Salamanca, el parque Tayrona y de otros ecosistemas del país.

La lucha de estos años permite identificar tres actores fundamentales del Movimiento Ambiental Colombiano (Tobasura 2006):

1. Los creadores de pensamiento, en el cual se encuentran personas e instituciones. En rigor, son los organizadores, los líderes o militantes de movimientos, encargados de crear los "marcos de referencia" para la movilización de "adherentes" y simpatizantes, y también producir "paquetes ideológicos" para crear opinión pública a través de los medios de comunicación y de instituciones como universidades y organizaciones del Estado. Entre las personas se destacan: Augusto Ángel Maya, Julio Carrizosa Umaña, Jorge I. Hernández Camacho, el "Mono Hernández", Manuel Rodríguez Becerra, Gustavo Wilches Chaux, Aníbal Patiño y Francisco González L. de G., entre otros. Entre las instituciones debe destacarse la academia, en cabeza de las universidades con institutos como el IDEA de la Universidad Nacional, el IDEADE de la Universidad Javeriana, el Centro de Investigación Ambiental CIA, de la Universidad de Antioquia y otros institutos y centros de universidades del país.

2. Los orientados a la praxis, entre quienes cabe mencionar a Gonzalo Palomino, Margarita Marino de Botero, Guillermo Castaño, Luis Alberto Ossa Patiño, Javier Márquez, Hildebrando Vélez, Juan Pablo Ruíz, entre otros. Por las características de las acciones realizadas, éstos han contribuido a la creación de identidad del movimiento; en cuanto sus acciones de hecho, generan símbolos, solidaridades y memoria colectiva compartida. En cierto sentido, pueden considerarse líderes u organizadores del movimiento o, si se prefiere, como la vanguardia, en la medida en que orientan la defensa de los bienes públicos. Aquí también cabe destacar a las organizaciones No Gubernamentales Ambientales ONGA y los movimientos y luchas de los campesinos y grupos étnicos.

3. Los orientados a la política, entre quienes sobresalen: Gustavo Wilches Chaux, Alegría Fonseca, Juan Mayr Maldonado, Manuel Rodríguez Becerra, Margarita Flórez, Carlos Fonseca Zaráte, Pablo Leyva, entre otros. A pesar de que éstos han actuado dentro de los partidos tradicionales y, excepcionalmente, algunos asumiendo la vocería de los ambientalistas, su influencia en la agenda pública ha contribuido a la generación de oportunidades políticas e institucionales, en la medida en que sus acciones han llegado a permear el poder del Estado dando lugar a nuevas instituciones y políticas. La incursión de los ambientalistas como movimiento político independiente en la arena política ha sido marginal. En la Asamblea Nacional Constituyente de 1991 no lograron escaño. En las tres últimas elecciones locales y regionales varios candidatos a las corporaciones públicas y a las alcaldías municipales enarbolando banderas "verdes" lograron el favor del electorado. El candidato del Partido Verde Oxígeno fue electo Alcalde del Caguán, en plena zona de distensión.

\section{AUGUSTO ÁNGEL MAYA (AAM): PENSADOR AMBIENTAL}

Ángel Maya, es uno de los pensadores más sobresalientes del emergente pensamiento ambiental en Colombia. Ha contribuido de manera notable a la consolidación del pensamiento y movimiento ambiental colombiano en los últimos 40 años. Sus aportes se pueden sintetizar en dos: el primero es la reflexión teórica y conceptual para entender lo ambiental desde una perspectiva política, social y cultural. El segundo es la creación de herramientas de trabajo político como la educación en una dimensión ambiental y el impulso a la organización nacional del Movimiento Ambiental MA, que aún no ha logrado consolidarse, al menos, en la óptica que él lo proponía.

\section{LA REFLEXIÓN TEÓRICA. APORTES AL PENSAMIENTO AMBIENTAL}

Como sus contemporáneos AAM vivió de cerca la efervescencia de los años 60 , donde participó en las luchas estudiantiles desde la concepción marxista clásica y desde una visión diferente de la juventud, que defendía valores como el amor libre, la naturaleza, la 
libertad, y que dieron origen a muchos de los movimientos sociales actuales como el ambientalismo. Su visión marxista inicial la matizó luego hacia un ambientalismo de tipo cultural, debido al énfasis desarrollista del marxismo, elaborando una perspectiva ambiental desde la cultura, apoyado en Hegel, Nietzsche y en otros pensadores de la Escuela de Frankfurt (Álvarez T. 1997).

Aunque sus reflexiones acerca de las interacciones sociedad-naturaleza las había comenzado como docente en la Universidad Jorge Tadeo Lozano, años atrás, su encuentro con el incipiente Movimiento Ambiental se dio en el Inderena en el año de 1973 como Director de la División de Desarrollo Social y Vigilancia, al lado de Julio Carrisoza Umaña. Allí se gestó la primera etapa del ambientalismo, con la educación ambiental o mesológica como la denominó la UNESCO. Se planteó también el debate entre la visión conservacionista de los técnicos, biólogos e ingenieros y la visión ambiental de la cultura que se gestaba en el pensamiento de AAM, configurando una tendencia tecnocrática de derecha y una postura crítica de izquierda. No una corriente de izquierda en sentido estricto, más sí una mirada de lo ambiental como problema social y político, la verdadera esencia del movimiento ambiental.

Después de 1978, AAM trabajó en el Ministerio de Educación en un proyecto de educación para indígenas y colonos en los territorios nacionales, donde continuó desarrollando su perspectiva ambiental. En dicha mirada, la Educación Ambiental (EA) implicaba un estudio detallado de las circunstancias geográficas y ecológicas en las que se construye la cultura, sin lo cual es imposible construir culturas adaptativas. Pero no es suficiente -dice Ángel Maya- porque el conocimiento de los sistemas ecológicos, geográficos y de los ecosistemas no indica cómo debe construirse la cultura, a lo sumo permite comprender las interacciones que se dan entre los seres humanos con su entorno (Álvarez T. 1997).

Ángel Maya es uno de los pioneros en demostrar en el país la aplicación de las ciencias sociales a la comprensión de los asuntos ambientales. Se dedicó a estudiar la historia del medio ambiente y lo diferente que era el trato que le daban los indígenas a sus territorios de aquel que le daban los colonizadores. Parte de ello lo logró en el trabajo con el Ministerio de Educación. La otra parte la alcanzó metido en el corazón de la Sierra Nevada de Santa Marta, donde insistió en la importancia de preservar la naturaleza y las etnias que allí prevalecen. La selva ha sufrido mucho y seguirá sufriendo debido al impacto de los cultivos de coca, de las fumigaciones y de la colonización, como consecuencia de la apertura de la frontera agrícola. $Y$ dado que los indígenas no tienen manera de defenderse, y la selva mucho menos, enfatiza en el cuidado que se debe tener con ellos y con su entorno.

Pero el deterioro ambiental no sólo se está provocando a la selva y a los ecosistemas: el impacto de los efectos del desarrollo y el estilo de vida de la sociedad actual, se siente también en los centros urbanos, donde el aire y el ruido afectan la calidad de vida. La contaminación está alcanzando los peores niveles de la historia. Las medidas de pico y placa y el uso de combustibles menos contaminantes adoptadas por algunas ciudades no son suficientes, si no hay una conciencia sobre los graves problemas generados por nuestro actual estilo de vida. El cuidado del medio ambiente es responsabilidad de todos: del Gobierno y de los ciudadanos. En palabras de Ángel Maya: "La vida hay que preservarla en todas sus manifestaciones y aprovechar cada respiro de aire puro que tenemos para lograrlo". Buena parte de estas ideas se sintetizan en su libro El reto de la vida (Ángel Maya, 1995).

En otro de sus libros: La diosa Némesis. Desarrollo Social o Cambio Cultural (Ángel Maya 2003) AAM manifiesta una de las tantas preocupaciones que ha tenido: la construcción de un "pensamiento ambiental latinoamericano" y de esa manera lo expresó en la conferencia presentada en el Seminario Permanente sobre Pensamiento Latinoamericano "De Estocolmo a Río-92", celebrado en Santiago de Chile en 1993. Su planteamiento se sustenta en el hecho de que la crisis ambiental es percibida desde diferentes perspectivas de análisis que, en buena medida, determinan las soluciones planteadas. Si no fuera así y la tierra fuera homogénea, tal como lo pregonan los propagandistas de las soluciones globales, o los adalides del desastre, no tendría sentido hablar de un pensamiento ambiental latinoamericano. Pero dado que la crisis ambiental afecta de manera 
diferenciada las regiones y desde ellas es percibida igualmente de manera distinta, se justifica la emergencia de un pensamiento propio.

Habitamos una tierra dividida, tanto por las estrategias adaptativas de los biomas como por las formaciones culturales o, mejor aún, por la subordinación de las regiones dentro de las actuales estrategias de desarrollo. Dichos aspectos deben ser considerados para la formulación de un pensamiento latinoamericano. El primero tiene que ver con la ubicación geográfica de los biomas en el neotrópico. El segundo debe dar cuenta de las formas culturales adaptativas de las comunidades neolíticas del trópico, desarrolladas por las culturas aborígenes. El uno requiere el conocimiento de las características y potencialidades de los ecosistemas tropicales para la definición de sistemas productivos viables y sostenibles. El otro exige un cambio profundo en las estructuras de poder y, por tanto, en la dinámica de las formaciones culturales.

Esta reflexión latinoamericana no significa una ruptura con los modelos científicos heredados de occidente, más sí una reformulación de dichos modelos. Tampoco significa el retorno a una especie de tribalismo ambiental, similar al de muchas culturas precolombinas que predominaba antes de la conquista, pero sí de una revisión profunda de los modelos de desarrollo, más de lo que esperan los orientadores de la política ambiental mundial y regional.

La formulación de este pensamiento quizás haya que hacerla a la manera de una dolorosa ruptura. La domesticación de las maneras de pensar, inducidas por la homogenización de la cultura occidental, dificulta enormemente la formulación de nuevos modelos de pensamiento. "No se trata tampoco de una pretensión esnobista de originalidad. Lo que debe buscar el pensamiento ambiental latinoamericano no es tanto entrar en la liza inútil de la competencia académica, sino buscar modelos que permitan alcanzar soluciones a los grandes problemas de la región", dice Ángel Maya.

Significa también una ruptura con las fuerzas instaladas al interior del subcontinente. Sobre modelos económicos imitativos, se han consolidado esquemas imitativos de pensamiento. Y la imitación o la copia no significan necesariamente armonía. De hecho, lo que se ha venido consolidando en América Latina y en el Tercer Mundo es una alocada carrera competitiva, impulsada por la falsa esperanza de alcanzar las metas de desarrollo vigentes en el mundo industrializado. Tantos años intentando "ser como ellos", no han sido suficientes para comprender que el modelo de sociedad occidental no es sustentable ni defendible en los tiempos que corren.

La preocupación de AAM por construir el pensamiento ambiental la retoma en el libro "El Retorno de Ícaro: Muerte y Vida de la Filosofía" (Ángel Maya 2001). Dicha obra es el ensayo conclusivo de la serie "La Razón de la Vida", en la que el autor ha venido realizando un análisis detallado de la historia del pensamiento filosófico. En los tres primeros volúmenes analiza los aportes de la filosofía griega. En el cuarto, estudia las contingencias del neoplartonismo y en el quinto, las principales tendencias de la filosofía moderna. No se trata sólo de la crítica a las diferentes tendencias filosóficas, sino que presenta a la discusión pública una propuesta que acoge los principales elementos del método de interpretación ambiental desarrollados en buena parte de su obra anterior. Bajo la visión de que la crisis ambiental no se resuelve sólo con un acople del aparato tecnológico o una reforma de las recetas económicas sino que exige una transformación profunda de los contenidos filosóficos y éticos, Ángel Maya escudriña los fundamentos filosóficos de la cultura, de donde debe partir la construcción del pensamiento ambiental latinoamericano.

En El reto de la vida: ecosistema y cultura. Una introducción al estudio del medio ambiente. Ángel Maya pone en evidencia la crisis ambiental que vive el mundo contemporáneo: los hechos son inocultables. El hombre contemporáneo está sintiendo la crisis ambiental en todos los rincones de la vida cotidiana. El agua escasea. La basura se acumula. Cada vez es más remota la posibilidad de encontrar una playa o un río limpios. Sin embargo, el problema ambiental no es sólo una crisis del hombre moderno. Durante el paleolítico, cuando era cazador, el hombre inventó armas cada vez más potentes y acorralaba con fuego a sus presas. En seiscientos millones de años que llevaba la vida, 
no se había visto un espectáculo igual. Visto en retrospectiva, el hombre paleolítico nos parece un estúpido primitivo. Sin embargo, era un innovador asombroso. Con él empezaron los problemas ambientales.

Muchos siglos después, ese cazador tuvo que convertirse en agricultor. No se contentó con cazar o con extraer de la naturaleza su sustento, sino que empezó a transformarla hasta límites insospechados. Escogió unas cuantas especies y las separó de otras que crecían con ellas. Doméstico unos pocos animales para aprovechar su carne, leche, piel fuerza o compañía. Y con la agricultura, inició la transformación más dramática de los ecosistemas.

Los principales problemas ambientales que enfrentó el hombre hasta la revolución industrial moderna estuvieron relacionados con la caza y la actividad agrícola. Las circunstancias no variaron mucho hasta finales del siglo XVIII. En ese momento la principal fuente de energía utilizada por el hombre era la fuerza animal y humana. Hoy, todavía se ve uno que otro equino en nuestras ciudades o en áreas de caminos destapados cargando pesadas cargas o arrastrando folclóricas carretas.

El panorama, sin embargo, se ha modificado drásticamente. Hoy en día el hombre utiliza sólo una mínima proporción de energía animal y humana. Las máquinas automatizadas han reemplazado a los bueyes y a las mulas y, en muchos casos, a la energía humana; pero las máquinas necesitan también energía. La revolución industrial moderna ha sido ante todo una revolución energética. El desarrollo moderno se ha basado fundamentalmente en la energía fósil. El hombre ha desenterrado durante dos siglos los gigantescos depósitos de plantas y animales que habían sido sepultados durante millones de años en las entrañas de la tierra.

La agradable facilidad de la vida moderna se está pagando cara. La tecnología ha ahorrado esfuerzo humano, pero en ocasiones puede resultar nefasta para el equilibrio de la vida e incluso para el bienestar del hombre. Los aerosoles evitan el pequeño esfuerzo de accionar una bomba manual para dispersar los insecticidas caseros, pero están debilitando la capa de ozono, ese escudo atmosférico que defiende la vida de los rayos ultravioletas. El cáncer de piel hoy es una amenaza real.

La agricultura moderna ha aumentado de manera asombrosa la producción de alimentos, de tal manera que la producción de granos ha venido creciendo más que la población humana, dejando sin validez real la tesis de Malthus, según la cual mientras la población crecía de manera geométrica, la producción de alimentos lo hacía de manera aritmética. Sin embargo, en 1962, cuando Raquel Carson publicó La Primavera Silenciosa, uno de los primeros gritos ambientalistas modernos, los agroquímicos amenazaban con envenenar el mundo. $\mathrm{Y}$ hoy, pese a que hay alimentos suficientes, millones de pobres mueren de hambre o viven desnutridos.

El crecimiento de las ciudades se ha tomado justamente como un signo de modernización. América Latina y en particular Colombia, han invertido las proporciones entre población rural y urbana en menos de cincuenta años. Sin embargo, el crecimiento de las ciudades en los países pobres y la falta de solución a sus problemas ambientales pueden significar en el futuro, si no está significando ya, un punto de estrangulamiento del desarrollo moderno y un deterioro paulatino de la calidad de vida.

Por otra parte, la población sigue creciendo en forma desequilibrada. Mientras los países industrializados mantienen estable el número de habitantes o incluso tienen tasas negativas de crecimiento, a costa de un envejecimiento de su población, los países del tercer mundo siguen creciendo a tasas por encima de su capacidad y posibilidad para mejorar la calidad de vida de las mayorías. Las ciudades latinoamericanas como Río de Janeiro, Lima, Ciudad de México, Bogotá, son verdaderos hormigueros de masas humanas.

La presión sobre los recursos naturales también se ejerce en forma desigual. Los sistemas boscosos y agrícolas mantienen un cierto equilibrio en los países de la zona templada, en cambio, los ritmos de deforestación en los países tropicales constituye uno 
de los principales problemas ambientales modernos. Como contraprestación, los países industrializados se han venido sumergiendo en un vaho espeso de contaminación. Sus bosques se están muriendo no descuajados por el hacha del colono, sino enfermos por el efecto de la lluvia ácida. Igualmente, las ciudades están siendo sepultadas por la basura. Tampoco hay dónde depositar los residuos peligrosos.

Se han mencionado sólo algunos de los efectos del desarrollo y del estilo de vida moderno, pero hay muchos más. Podría citarse el envenenamiento de las fuentes de agua, el deterioro de los suelos agrícolas y los procesos de erosión que sepultan la tierra fértil en los fondos marinos. La crisis ambiental no responde, por tanto, a una falsa alarma. Es algo que está presente en la vida diaria y que quema la piel. Sin embargo, la ciencia no ha logrado todavía explicar con claridad los hechos. Se ha intentado dar explicaciones, la mayoría de ellas parciales. Muchas explican sólo porciones estrechas de la realidad.

La ciencia moderna no está hecha para explicar sistemas, sino para desmenuzarlos como las piezas de un mecano. Por una parte las explicaciones que provienen de la biología y la ecología no saben qué hacer con el hombre. Su comportamiento no cabe en las leyes rigurosas que presiden el funcionamiento de los ecosistemas. Los ecólogos no han podido encontrar el nicho del hombre. A primera vista parece un rebelde de la naturaleza, un ser antinaturaleza.

Lo antes descrito tiene como propósito orientar hacia la comprensión de la crisis ambiental. Los hechos son dramáticos, crudos, insobornables. ¿Cómo explicarlos? Ese es el propósito de AAM en El reto de la vida: ecosistema y cultura. Una introducción al estudio del medio ambiente. Allí presenta una explicación sencilla, para comprender el problema ambiental; una manera que abarca la totalidad de la vida, incluso la del hombre mismo y la de la cultura.

La propuesta de AAM supera las visiones restringidas que interpretan lo ambiental como un problema ecológico o exclusivamente tecnológico, esta propuesta intenta comprenderlo como un objeto de estudio de todas las disciplinas científicas, desde las ciencias naturales y tecnológicas, hasta las ciencias que estudian el comportamiento humano. El problema ambiental es responsabilidad de todos y debe ser tratado de manera integral.

\section{SU PRAXIS: UNA APUESTA A LA ACCIÓN POLÍTICA}

Aunque la génesis del Movimiento Ambiental Colombiano MAC podría remontarse a los tiempos de la conquista y de la colonia, su configuración con las características propias de los nuevos movimientos sociales data de finales de los años sesenta y setenta del siglo pasado. De hecho, hasta los años ochenta, había grupos y colectivos ambientales en Cali, Bogotá, Pereira, Medellín, Cauca, Popayán y Tolima, pero el Movimiento Ambiental no había celebrado ninguna reunión de carácter nacional. En el caso de Cali y Tolima, los grupos estaban ligados a la universidad por iniciativa de profesores como Hernando Patiño, Gonzalo Palomino y Aníbal Patiño. En Pereira, el movimiento gravitaba entorno a Guillermo Castaño y a Luis Alberto Ossa, quienes lideraban un movimiento de izquierda, cercano a lo que en nuestros días constituye el "Ecologismo de los Pobres" o el movimiento de "Justicia Ambiental".

Al respecto, AAM dice que los MA de las universidades dependen mucho de personalidades, como han sido los casos de Aníbal Patiño en a Universidad del Valle, Hernando Patiño en la Universidad Nacional de Palmira y Gonzalo Palomino en la Universidad del Tolima. Si bien ellos han dejado un legado muy importante al pensamiento a y la praxis ambiental y han contribuido a formar una pléyade de ambientalistas, sus iniciativas han venido eclipsándose con el paso del tiempo, en muchos casos hasta quedar en el olvido. Por otra parte, los movimientos académicos no dan origen a movimientos ambientales, como son los casos del Instituto de Estudios Ambientales IDEA de la Universidad Nacional y el Instituto de Estudios Ambientales para el Desarrollo IDEADE de la Universidad Javeriana, que si bien han contribuido a crear una masa crítica con una concepción de lo ambiental más compleja, no han dado origen a movimientos, configurándose una escisión entre lo académico y los movimientos ambientales, es decir, entre el pensamiento y la praxis ambiental. 
En 1983 se celebró en Pereira ECONGENTE, primer encuentro nacional de ambientalistas. AAM asistió pero no como funcionario del Programa de las Naciones Unidas para el Medio Ambiente PNUMA, porque desde 1981 estaba vinculado a la Naciones Unidas; no obstante, algunos le preguntaron qué hacía este organismo allí, y llegaron a pensar, incluso, que se trataba de un espía. "Como ya manejaba la concepción de que lo ambiental era más que lo ecológico, mi presencia despertó todavía más sospecha, pues se entendió como una intromisión de las Naciones Unidas, que quería desvirtuar el movimiento político que se trataba de gestar", dice AAM.

En vista de que el ecologismo de la época era conservacionista y técnico, poco político, planteó la posibilidad de crear un movimiento ambiental que superara la visión conservacionista instrumental, pues lo ambiental era más, mucho más, que el conservacionismo puro que propugnaban los ambientalistas de la corriente tradicional, heredera de John Muir y el Sierra Club de Estados Unidos; el ambientalismo era producto de las relaciones que surgían entre los seres humanos por el acceso y uso de los recursos, es decir, los procesos sociales surgidos en la adaptación y transformación del entorno, o dicho de otra forma, las relaciones de poder emanadas de dichos procesos.

Pese a que no se avanzó mucho en ECONGENTE, se sembraron y alimentaron los ideales para crear un movimiento ambiental de corte nacional, como hoy todavía se sigue soñando. En concreto se creó un Comité Nacional y los Grupos Ecológicos de Risaralda GER empezaron a impulsar la unificación y consolidación del movimiento. Luego vinieron los encuentros de Cachipay en 1985 y de Guaduas 1992, como preparación a la cumbre de Río-92. En los años 1999, 2000, 2001 y 2002, se han realizado encuentros, congresos, foros, regionales y nacionales, con miras a consolidar el Movimiento Político Ambiental Colombiano sin cristalizar la iniciativa, pero se ha mantenido viva la esperanza y la ilusión de avanzar en esa dirección.

Como ya se anotó, en 1981, AAM ingresó a trabajar en el PNUMA, en México, donde permaneció hasta 1986. A mi regreso de México-dice-, con una idea más clara de lo que podría ser un movimiento político ambiental, propicié el acercamiento a grupos que pudieran recoger las banderas del MA e incorporarlas en su programa político. Uno de esos grupos era el M-19 cuando estaba en el proceso de desmilitarización en Santo Domingo, pero el intento fracasó, pues el ideario ambiental no era compatible con los intereses y la propuesta política del M-19 en ese momento. Luego se intentó en la constituyente de 1991, pero tampoco respondieron. No comprendieron el signo de los tiempos y la importancia política que tenía lo ambiental (Ángel Maya, 1997).

Surgió, entonces, la idea de participar con candidato propio en la Constituyente de 1991. En un principio, se postuló a Ángel Maya, pero no aceptó, ante lo cual se propuso a Gustavo Wilches Chaux, en alianza con los indígenas del Cauca. No se logró la unidad, pese al carisma y al reconocimiento de ambientalista que tenía Wilches Chaux en el país. Se puso en evidencia la imposibilidad de cohesión nacional para alcanzar una representación política del MA. En consecuencia, el candidato de los ambientalistas obtuvo 8000 votos, sin alcanzar escaño en la Constituyente.

Pero las ideas de los ambientalistas que no habían encontrado eco en la izquierda, paradójicamente fueron acogidas por los liberales del nuevo liberalismo en cabeza de Iván Marulanda, quienes pidieron asesoría y lograron incorporar buena parte del ideario ambientalista. De hecho, la Constitución Política de 1991 se ha considerado una Constitución "verde", por su contenido ambiental. El capítulo de los derechos colectivos y del ambiente (artículos 78 a 82) en buena parte recogió el ideario del MA de la época.

Mi intención -dice AAM- era que el movimiento ambiental incursionara en la arena política, involucrar lo ambiental en la agenda pública, pero las circunstancias del momento no lo permitieron. Aparecieron muchos avivatos buscando pescar en río revuelto, como Guillermo Alemán, que se candidatizó a la presidencia de la república en 1994 y 1998, con la pretensión de obtener réditos políticos de los ambientalistas. En general, la incursión de los ambientalistas como movimiento político independiente en la arena política ha sido poco exitosa. En las últimas elecciones locales y regionales varios candidatos a las corporaciones públicas y a las alcaldías municipales enarbolando banderas verdes 
lograron el favor del electorado. El candidato del Partido Verde Oxígeno fue electo Alcalde del Caguán, en plena zona de distensión. Los candidatos del Comité Ecológico del municipio de Risaralda (Caldas) (CER) fueron electos concejales de su municipio en los años 1996 y 1998. En las elecciones parlamentarias de 2006, el candidato de "Iniciativa Ambiental", apenas superó los 2000 votos. Pese a estos intentos de incursión en el debate electoral, el movimiento ambiental colombiano aún está biche para ser verde, es decir, para constituirse en partido político independiente.

La pretensión de AAM no era crear un movimiento político independiente, sino establecer alianzas con otros grupos que defendían los derechos de las minorías, como los indígenas y los afrodescendientes. Con esta experiencia, AAM, pasa del moderado optimismo que lo había caracterizado en tanto su persistencia en la creación y consolidación del movimiento ambiental, a la mesurada frustración o decepción que lo llevó a vincularse entre 1993 y 1995 con el Movimiento Ambiental del Ecuador, mientras dirigía el Instituto de Estudios Ambientales IDEA, que había contribuido a crear en la Universidad Nacional de Colombia.

La pérdida del rumbo del MA ha hecho que algunos de los líderes más lucidos llamen la atención acerca de la desnaturalización de la lucha que dio origen a estos colectivos en los años setenta. La situación es muy compleja debido a la proliferación de organizaciones y a la diversidad de matices que existen. Los múltiples encuentros que se han realizado señalando principios y derroteros no han sido suficientes para lograr la cohesión del Movimiento Ambiental (Vélez 2001). Hoy, las organizaciones no gubernamentales ambientalistas (actor más visible del ambientalismo) parecen estar más obnubiladas por la búsqueda de recursos para su supervivencia que por encontrar el horizonte que las oriente en la construcción de una praxis ambiental más acorde con los problemas y la historia del país.

Hoy, a diferencia de los años setentas y de los primeros años de la década del ochenta, el movimiento ambiental es apenas un pálido reflejo, constituido, en su mayoría, por un archipiélago de organizaciones no gubernamentales que se mueven entorno a proyectos educativos, productivos, de gestión ambiental urbana y de conservación de la biodiversidad. La capacidad de movilización de masas ha desaparecido de los repertorios de acción, y la estructura de las organizaciones de movimiento hoy es de carácter burocrático, con predominio de la figura de ONG ambientalista.

Los últimos encuentros de ambientalistas han buscado por todos los medios retomar el camino perdido, pero la diversidad de intereses y de posturas ideológicas, éticas, estéticas y políticas, ha sido más fuerte que las intenciones y el entusiasmo de los ambientalistas. Pese a tener hoy más "adherentes" y simpatizantes, el ambientalismo, paradójicamente, es más débil, en el sentido de haber extraviado su horizonte ideológico y político de lucha. De hecho, hoy es fácil diferenciar ambientalismos de todos los matices, desde los recalcitrantes neoliberales, incluso los de extrema derecha, hasta los más espiritualistas y románticos; muchos de ellos, sin liderazgo y capacidad de acción política (Tobasura 2006).

Ángel Maya, respecto a la crisis del MAC, dice: lo que ha pasado después de Río-92 es que todo el mundo se montó en el carro de lo ambiental sin saber nada, sin conocimiento y sin formación alguna, desde los ministros del Medio Ambiente, hasta muchos miembros de ONG ambientales. Hasta antes del Gobierno Uribe, todos los Ministros del Medio Ambiente que hemos tenido (excepto Juan Mayr Maldonado) no han tenido ni idea de Medio Ambiente. Prometían muchas cosas, invocando términos como "desarrollo sostenible", sin saber de qué se trata. Hoy, en Colombia, todo el mundo habla de desarrollo sostenible sin saber en qué consiste, cuáles son sus indicadores y sus efectos ${ }^{1}$. El desarrollo sostenible es un concepto vago, sin contenido, o cuando mucho un cajón de sastre donde cabe todo.

El asunto ambiental se ve muy distinto en el Ministerio de Hacienda que en el Ministerio del Medio Ambiente, o que en el ECOFONDO. Hay mucho interés del gobierno en absorber el MA, eso se ve mucho en las diferentes organizaciones ambientales. De hecho hoy se podría hablar de un "ambientalismo oficial", neoliberal y autoritario. Hay algunos 
que resisten y son los héroes en esta época, pero no son muchos. El movimiento ambiental es un movimiento mundial que va llegando y calando en todos los países. Podría decirse como en otros tiempos: "un ismo recorre el mundo, ese ismo es el ambientalismo". Infortunadamente ese movimiento se oculta bajo el nombre de Desarrollo Sostenible de Brudtland 1987. Y eso es trágico, porque es no entender el problema ambiental en su real dimensión. Eso lleva a aceptar, por ejemplo, George W. Bush, siendo el Presidente del país que emite el $60 \%$ de los gases "efecto invernadero", no haya suscrito el protocolo de Kyoto. Es no entender que, amparados en la retórica del desarrollo sostenible, se ocultan los intereses económicos de los organismos multilaterales y de las transnacionales, que están detrás de la destrucción de la tierra.

Sin duda alguna ha aumentado la importancia de lo ambiental a nivel político, social, y en los medios de comunicación. Hoy hay muchos más ciudadanos sensibilizados, pero no suficientemente capacitados. Ha faltado un esfuerzo de formación profesional para profundizar en lo que es el medio ambiente y en lo que significa la crisis ambiental, debido, en buena parte, a que la universidad no ha respondido al reto ambiental, está muy atrasada en la comprensión y en el análisis de lo ambiental. Se requiere que la universidad y el sistema educativo asuman el compromiso de la formación ambiental en el país. En palabras de Ángel Maya, "Para mí, hay tres dimensiones en las que hay que seguir profundizando: el medio ambiente en la organización de las sociedades; la naturaleza como motor social y por último demostrar cómo la naturaleza se venga del daño del hombre a través de las catástrofes naturales"2.

El problema del medio ambiente no es sólo tecnológico sino social y simbólico; por lo tanto, se necesita estudiar cómo influye una determinada forma de organización social en el medio ambiente, y también, cómo afecta la concepción ideológica nuestro comportamiento ambiental. Muchos de los problemas que tenemos no son de tipo tecnológico, sino de carácter ideológico. El desprecio hacia la naturaleza, una visión platónica sobre una naturaleza corruptible que vale la pena conservar, que ha caminado en occidente y los problemas de organización social que son definitivos para entender la problemática ambiental, es lo que busca la propuesta ambiental de Ángel Maya. Trata de dar elementos a los profesores para comprender lo tecnológico, la organización social, política y económica, y la repercusión simbólica en los problemas del medio ambiente. Sólo de esa manera podremos contribuir a la defensa de la naturaleza y a generar estilos de vida más aptos para la conservación de la vida y el bienestar humano.

Para superar la crisis ambiental -insiste Ángel Maya (2001)- es necesario formular las bases de una nueva cultura. Es una tarea difícil pero no inalcanzable. E1 hom $\neg$ bre se ha visto muchas veces sometido a la exigencia de cambios culturales profundos, que involucran no solamente la superficie tecnológica o el tejido social, sino igualmente ese extraño tejido simbólico que le permite a la cultura reproducirse y luchar por sobrevivir El cambio del paleolítico al neolítico vio morir no solamente las tecnologías de caza, sino también a los dioses ancestrales. El nacimiento de la filosofía Jonia surgió como una exigencia de cambio cultural frente a símbolos que ya no correspondían a las nuevas circunstancias sociales.

En la actualidad se siente cada vez con mayor exigencia la necesidad de legislaciones más radicales, para controlar el deterioro del medio. Por lo general los cambios en la norma jurídica son precursores de nuevas prescripciones éticas $y$ de profundas renovaciones filosóficas. La filosofía Jonia fue en parte una respuesta a los profundos cambios que introdujeron los juristas griegos durante e1 siglo VII y Aristóteles renació en el siglo XIII, para dar base filosófica al nuevo derecho de las comunas. Si los legisladores introducen el concepto de propiedad privada o de libertad individual, la filosofía tiene que justificarlos.

Estamos quizás en un momento similar. Las normas éticas y jurídicas han sido construidas en Occidente sobre la base de una naturaleza sometida. Según la filosofía kantiana, sólo el hombre es sujeto de derecho. ¿Supone ello que el hombre puede transformar a su entero arbitrio el medio natural? ¿Cuáles son los límites de la acción huma $n$ na, vistos ya no solamente desde el punto de vista de la organización social, sino desde su relación con las leyes que rigen la naturaleza? Y si existen esos límites, ¿significa ello que el hombre tiene normas externas a su propia organización social? 
¿Hasta qué punto una respuesta positiva puede remover los cimientos de la filosofía occidental anclada en la dicotomía entre hombre y naturaleza?

\section{BIBLIOGRAFÍA}

- ÁlVAREZ Tamayo, J. H. 1997. Movimiento Ambiental Colombiano: Como un pájaro blanco cegado por la nieve. En: Se hace camino al andar, Aportes para una historia del Movimiento Ambiental Colombiano. Ecofondo. (Bogotá). 238 p.

- ÁNGEL MAYA, A. 1995. El Reto de la Vida: Ecosistema y Cultura. Una Introducción al Estudio del Medio Ambiente. Ecofondo (Bogotá).

- $\quad$ de Occidente (Cali). 294 p.

- $\quad$---or La diosa Némesis. Desarrollo Social o Cambio Cultura. Corporación Autónoma de Occidente- (Cali). 407 p.

- $\quad$ J.H. ed. Se hace camino al andar. Aportes para una historia del movimiento ambiental en Colombia. (Editor). ECOFONDO. (Bogotá). P. 51-69.

- TOBASURA ACUÑA, I. 2006. Ambientalismos y ambientalistas. El ambientalismo criollo a finales del siglo XX. Universidad de Caldas. (Manizales). 395 p.

- VÉlEZ G., H. 2001. Elementos políticos y programáticos del movimiento ambientalista. En: Hacia la construcción del movimiento nacional ambientalista. Bogotá. 64 p.

\section{NOTAS}

1. Augusto Ángel Maya. Entrevista. Cali, abril 21 de 2001.

2. Entrevista realizada por Elizabeth Yarce, titulada Filósofo de profesión, ecólogo de corazón. www. elcolombiano ejemplar.org/premio2006/ganadores/medioambiente_personahtm. Mayo de 2008. 